OPEN ACCESS

Edited by:

Ute Frevert,

New York University School

of Medicine, USA

Reviewed by:

Paul Fisch,

University Freiburg Medical Center,

Germany

Sergio Schenkman,

Universidade Federal de São Paulo,

Brazil

${ }^{*}$ Correspondence:

Alexandre Morrot

morrot@micro.ufri.br

Specialty section:

This article was submitted to Microbial Immunology,

a section of the journal

Frontiers in Microbiology

Received: 23 November 2015

Accepted: 04 March 2016

Published: 23 March 2016

Citation:

Nardy AFFR, Freire-de-Lima CG,

Pérez AR and Morrot A (2016) Role

of Trypanosoma cruzi Trans-sialidase

on the Escape from Host Immune

Surveillance. Front. Microbiol. 7:348.

doi: 10.3389/fmicb.2016.00348

\section{Role of Trypanosoma cruzi Trans-sialidase on the Escape from Host Immune Surveillance}

\author{
Ana F. F. R. Nardy', Celio G. Freire-de-Lima ${ }^{2}$, Ana R. Pérez ${ }^{3}$ and Alexandre Morrot ${ }^{1 *}$ \\ ${ }^{1}$ Institute of Microbiology, Federal University of Rio de Janeiro, Rio de Janeiro, Brazil, ${ }^{2}$ Carlos Chagas Filho Institute of \\ Biophysics, Federal University of Rio de Janeiro, Rio de Janeiro, Brazil, ${ }^{3}$ Institute of Clinical and Experimental Immunology of \\ Rosario, CONICET, National University of Rosario, Rosario, Argentina
}

Chagas disease is caused by the flagellate protozoan Trypanosoma cruzi, affecting millions of people throughout Latin America. The parasite dampens host immune response causing modifications in diverse lymphoid compartments, including the thymus. T. cruzi trans-sialidase (TS) seems to play a fundamental role in such immunopathological events. This unusual enzyme catalyses the transference of sialic acid molecules from host glycoconjugates to acceptor molecules placed on the parasite surface. TS activity mediates several biological effects leading to the subversion of host immune system, hence favoring both parasite survival and the establishment of chronic infection. This review summarizes current findings on the roles of TS in the immune response during T. cruzi infection.

Keywords: Trypanosoma cruzi, trans-sialidase, parasites, immune evasion, glycoimmunology

\section{INTRODUCTION}

The protozoan parasite Trypanosoma cruzi (T. cruzi) is the causative agent of Chagas disease. During their life cycle, T. cruzi acquires different morphologies, alternating between an insect vector and the vertebrate host (Tarleton et al., 2007; Ribeiro et al., 2012). Vector-borne transmission occurs when infected bugs take a blood meal releasing simultaneously contaminated feces with infective metacyclic trypomastigotes near the site of the mammal bite wound (Tyler and Engman, 2001). Once inside the host, parasites differentiate to bloodstream trypomastigotes, which can infect host cells where they differentiate into intracellular amastigotes.

Besides vectorial transmission, other forms of infection exist, i.e., organ transplantation, blood transfusion as well as vertical and oral transmission. Chagas disease progresses from an initial acute phase characterized by a large number of circulating parasites and a broad range of symptoms (same individuals can develop fever, muscle pain, lymphadenopathy or an inflammatory reaction at the biting site known as chagoma), to a chronic and asymptomatic phase where the parasite load is nearly undetectable (Devera et al., 2003; Tarleton et al., 2007). Such latent stage could persist for the lifetime of individuals. However, nearly $30 \%$ of chronically infected individuals progress to a symptomatic disease, with the development of cardiomyopathy, megacolon, or megaesophagus (Coura and Borges-Pereira, 2010).

The parasite has evolved diverse mechanisms to subvert or escape from the host innate and adaptative immune system. One of them is the induction of an immunosuppressive state, which was described both during the acute phase of experimental and human T. cruzi infection (Oladiran and Belosevic, 2012). This condition is characterized by anergy or clonal deletion of T lymphocytes as well as polyclonal activation of B cells with production of low affinity antibodies against 
T. cruzi (Ortiz-Ortiz et al., 1980; Maleckar and Kierszenbaum, 1983). Thus, the inhibition of host immunity observed during the acute phase is an essential way for parasite persistence and the consequent establishment of chronic disease.

Sialic acids (SAcs) are a family of nine-carbon monosaccharides present on the surface of all mammalian cells, conferring diverse biologically activities to glycoproteins and glycolipids, like the promotion of cell-cell interactions or masking recognition sites due to its negative charge (Frasch, 2000). SAcs act as recognition receptors for diverse pathogens including viruses, bacteria and parasites (Varki, 1997; Esko and Sharon, 2009). Moreover, pathogenic bacteria like Escherichia coli $K 1$ and $N$. meningitidis synthesize SAcs and use it to decorate their surfaces to evade the immune system in their mammalian hosts (Vimr and Lichtensteiger, 2002). Unlike these microorganisms, T. cruzi is unable to synthesize SAcs de novo. Since T. cruzi requires SAcs to survive in the mammalian milieu, the parasite exploites the presence of SAcs on host cells, transferring the monosaccharide from host sialyl-glycoconjugates to terminal $\beta$-galactoses of acceptor molecules located on its own surface. This enzymatic activity is carried out by an unusual parasite enzyme known as trans-sialidase (TS), a modified sialidase (Previato et al., 1985; Freire-de-Lima et al., 2015).

TS displays a diversity of biological properties (many of them independent of their enzymatic activity), which promote the evasion of the innate and adaptative immune responses, acting as an important T. cruzi virulence factor (Burleigh and Andrews, 1995). The comprehension of mechanisms involving TS in the abrogation of immunity against $T$. cruzi infection is crucial for the developing and establishment of effective therapeutic approaches.

\section{Trypanosoma cruzi TRANS-SIALIDASE: A GLANCE ON ITS CHARACTERIZATION AND STRUCTURE}

The first description of the presence of SAcs residues on T. cruzi surface came from studies performed in the eighties (Pereira et al., 1980). Later, it was demonstrated that SAcs found on the parasite surface were previously transferred from the extracellular milieu, since no conventional precursors were found on parasites (Schauer et al., 1983). Furthermore, it was determined that trypomastigotes also displayed neuraminidase activity, because they hydrolyzed SAcs residues from erythrocytes and plasma glycoproteins (Pereira, 1983). Finally, Previato et al. (1985) demonstrated that $T$. cruzi performs the enzymatic transference of SAcs by an alternative route involving a transglycosylation reaction. Subsequent studies demonstrated that such trans-glycosylase activity is specific for alpha $(\alpha) 2,3-S A c s$ (Schenkman et al., 1991). Further, genetic studies performed to characterize T. cruzi-TSs genes showed that trans-sialidase and neuraminidase activities were associated to the same parasite enzyme (Pereira et al., 1991; Parodi et al., 1992; Uemura et al., 1992).
Trypanosoma cruzi-TS is part of the TS-superfamily, encoded by 1430 genes. There have been characterized $\sim 15$ genes for enzymatically active-TS, and more than 700 for the inactive-TS which lack the catalytic domain; while the rest are pseudogenes (Atwood et al., 2005; El-Sayed et al., 2005). Moreover, TSsuperfamily was recently classified by genomic analysis in eight groups. Active-TS members belong to the group-I, while inactiveTS members belong to groups-II to VIII (Freitas et al., 2011).

The general TS protein structure derived from metacyclic and bloodstream trypomastigote forms shows two major regions. As seen in Figure 1, one region is a N-terminal catalytic region whereas the other one consist of a $\mathrm{C}$-terminal region displaying repeats of 12 amino acids in tandem, called SAPA (by Shed Acute Phase Antigen) (Pollevick et al., 1991). The hydrophobic catalytic pocket, responsible for the interaction of transferred SAcs with the terminal $\beta$-galactose acceptor, is a three-dimensional structure rich in aromatic residues (Buschiazzo et al., 2002). Inactive-TS members belonging to the TS group II (Freitas et al., 2011) differ from the active ones in their $\mathrm{N}$-terminal region by the presence of mutations in catalytic residues causing the lack of enzymatic activity ( $\mathrm{Tyr}^{342}$ by $\mathrm{His}^{342}$ is the commonest mutation) (Figure 1B). These inactiveTSs are lectin-like proteins since they maintain the capacity of binding SAcs and $\beta$-galactose residues (Cremona et al., 1995, 1999; Oppezzo et al., 2011), and are involved in host cell attachment and invasion (Freitas et al., 2011). Furthermore, both TSs are surface glycophosphatidylinositol (GPI)-anchored molecules, which can be released into the bloodstream by the action of phosphatidylinositol phospholipase C on GPI-anchors (Schenkman et al., 1992).

\section{THE Trypanosoma cruzi TRANS-SIALIDASE IS ABLE TO OVERCOME THE FIRST LINE OF THE IMMUNE DEFENSES}

As sialic acid residues can be found on the surface of all mammalian cells, exerting crucial roles in regulating both innate and adaptative host immunity (Amon et al., 2014), it is not surprising that $T$. cruzi takes advantage of such host cell sialoglycophenotype. In this sense, in addition to transfering SAcs to the parasite surface, the TS can also transfer SAcs between host cell glycoconjugates, allowing the parasite to affect the host immune response (Figure 2).

The subversion of immune response by $T$. cruzi depends at first on their early action upon innate compounds. The host milieu is plenty of potential SAcs donors, allowing the parasite to acquire a negatively charged cover surface right after entering into the host, through the reaction catalyzed by TS. The fact of acquiring such negatively charged mask enables $T$. cruzi to circumvent the effects of some serum compounds (Vimr and Lichtensteiger, 2002). The elimination of this protective cover by sialidase treatment, make trypomastigotes more susceptible to the complement-mediated lysis (Kipnis et al., 1981). In addition, GPI-anchored surface GP160/CRP and T-DAF proteins, putative 


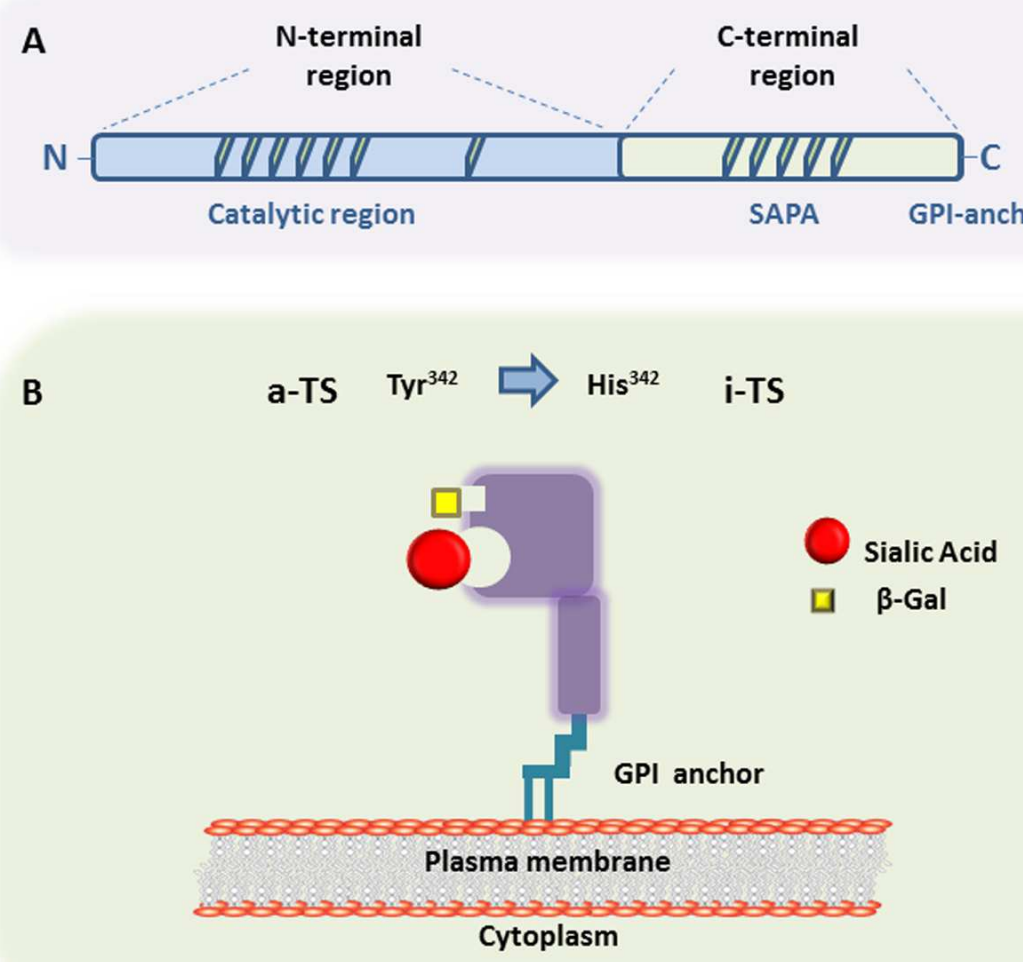

FIGURE 1 | Trans-sialidase structure. (A) Representative scheme of the primary structure of metacyclic- and a bloodstream trypomastigote-TS members belonging to either Group I (active-TS) or Group II (inactive-TS), showing the N-terminal and C-terminal domains. (B) Representative 3D structure of active (a-TS) and inactive (i-TS) forms of Trypanosoma cruzi-TS. T. cruzi-TS proteins are bound to the parasite surface through GPI-anchors. Active-TS sialylates parasite's mucin-like molecules, as well as host cell surface glycoconjugates. Inactive-TS in turn acts as a parasite adhesin and it is differentiated from a-TS by a single mutation in the catalytic residue of Tyrosine at the position 342, which is commonly changed by a Histidine.

members of inactive-TS family, conferred protection against the complement-mediating killing by avoiding C3 convertase assembly (Tomlinson et al., 1994; Norris, 1998) (Figure 2A). Furthermore, sialylglycoconjugates present on the parasite surface due to TS activity, can bind SAcs binding Ig-type lectins (Siglec-E) on dendritic cells, suppressing the production of the proinflammatory cytokine IL-12, thus impairing the central branch connecting the innate and adaptative immune responses and favoring immunosuppression (Erdmann et al., 2009) (Figure 2B).

Trypanosoma cruzi can infect any nucleated cell, including phagocytic cells. To facilitate the adhesion and invasion of mammalian host cells, T. cruzi parasites use different molecules, including TS (Barrias et al., 2013). The reduced ability of T. cruzi to invade SAcs-deficient cells compared to wild type cells, clearly show that key steps of parasitism, such as the adhesion and invasion of host cells require the participation of TS (Ming et al., 1993; Schenkman et al., 1993). Moreover, both active- and inactive-TS seem to participate in these steps (Barrias et al., 2013). After cellular binding, T. cruzi invades non-phagocytic host cells by diverse processes that alternatively require fusion of lysosomes at the site of entry, participation of plasma membrane components or fusion with endosome compartments at the site of invasion (de Souza et al., 2010; Barrias et al., 2013). Regardless of the mechanisms of infection, the parasite will be later located in a vesicle called parasitophorous vacuole (Tardieux et al., 1992; de Souza et al., 2010). The internal membrane of this organelle is enriched with highly sialylated LAMP proteins (Albertti et al., 2010). The acidic $\mathrm{pH}$ of the parasitophorous vacuole favors the activity of TS in transferring SAcs from LAMP proteins to the parasite surface. The desialyzation process renders the vesicle more prone to lysis by the action of Tc-Tox (a parasite-derived protein with membrane pore-forming activity), enabling the parasite to escape into the cytoplasm (Andrews and Whitlow, 1989; Hall et al., 1992; Rubin-de-Celis et al., 2006; Albertti et al., 2010) (Figure 2B).

Trypanosoma cruzi parasites can be also internalized via phagocytosis by macrophages, a process that triggers an oxidative burst to kill parasites (Alvarez et al., 2011). However, the parasite can avoid macrophage-induced cytotoxicity using an antioxidant complex system to ensure their escape into the cytoplasm in order to establish a productive infection (Piacenza et al., 2009; Nagajyothi et al., 2012). 
A- Complement system

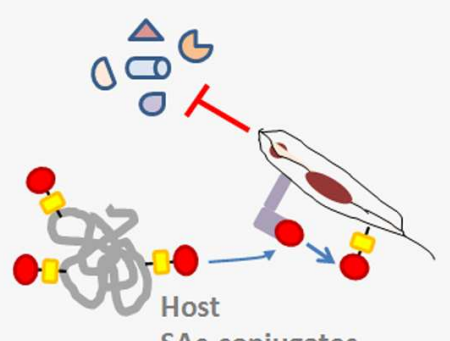

SAc-conjugates

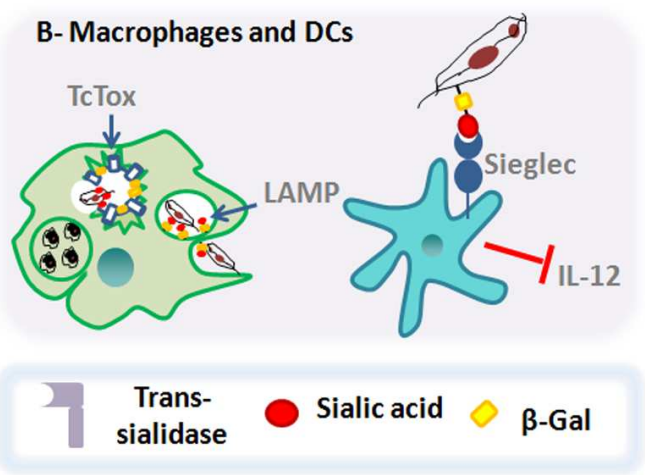

C- B cells
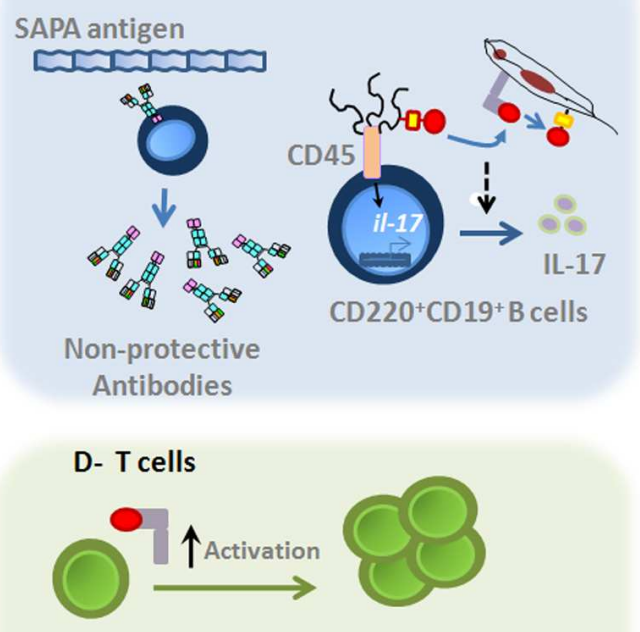

CD4 $\mathrm{T}^{+}$cell

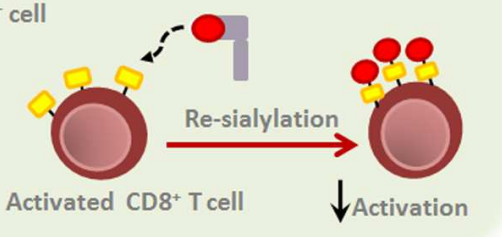

FIGURE 2 | Main roles of $\boldsymbol{T}$. cruzi TS on the host immune responses. (A) Upon entry in the host milieu, which is rich in SAcs donors, the parasite surface gets a negatively charged barrier due to a reaction catalyzed by TS, conferring protection against the complement-mediated killing. (B) TS favors T. cruzi escape from the parasitophorous vacuole, process in which LAMP and Tc-Tox proteins are also shown to be involved. Moreover, TS is able to interfere with IL-12 secretion by dendritic cells through the interaction between sialylated molecules on T. cruzi surface and Siglecs on dendritic cell surface. (C) SAPA-antigen induces the production of non-protective antibodies. Moreover, recent findings have show that TS acts on both mature follicular and marginal zone CD220 ${ }^{+} \mathrm{CD} 19^{+} \mathrm{B}$ cells to induce the expression of IL-17 by a non-canonical signaling pathway. These signaling events promote changes in the glycosylation profile of CD45 that result in their phosphatase activity and subsequent activation of downstream signals leading to the $/ 1-17$ gene expression. (D) TS can also induce the activation of CD4+ ${ }^{+}$cells in vivo. In addition, TS can also promote changes in the sialylation pattern of activated CD8 ${ }^{+} \mathrm{T}$ cells, dampening the protective functions of MHC class I-dependent lymphocyte killing responses against T. cruzi parasites.

Moreover, TS can also remodel the surface of surrounding host cells. As mentioned earlier, TS can be shed into the bloodstream, causing removal of SAcs located on platelet surface, an event that increases their clearance thus favoring the occurrence of thrombocytopenia (Tribulatti et al., 2005).

\section{Trypanosoma cruzi TRANS-SIALIDASE COMPROMISES BOTH B AND T CELL RESPONSES}

During the acute phase, it has been shown the involvement of TS in the polyclonal B-lymphocyte activation (Gao and Pereira, 2001). Probably, the B cell polyclonal activation may restrict the niche size required for an optimal development of specific and protective lymphocytes, by increasing the competition for activation and survival signals in the lymphoid organs (Freitas and Rocha, 2000; Montaudouin et al., 2013). Interestingly, the presence of immunodominant epitopes derived from shed acute phase antigens (SAPAs) shared by TS, drives the production of non-inhibitory antibodies against regions close to the catalytic site of the enzyme (Alvarez et al., 2001) (Figure 2C). These antibodies are produced in a $\mathrm{T}$ cell-independent manner, delaying the acquisition of inhibitory antibodies (Gao and Pereira, 2001; Gao et al., 2002). Importantly, these inhibitory antibodies are mainly neutralizing IgG immunoglobulins directed against the catalytic site of TS, and their production is strongly correlated with an IFN- $\gamma$ enriched milieu (Pereira-Chioccola et al., 1994; Ribeirão et al., 2000; Risso et al., 2007). It is possible that the SAPA antigens have evolved to avoid the production of protective antibodies directed against the $\mathrm{N}$-terminal catalytic region, since they are absent in the epimastigote forms. Additionally, these antigens are responsible to increase the half-life of TS shed into the bloodstream (Ribeirão et al., 1997; Buscaglia et al., 1999). Furthermore, the trypomastigote surface is rich in terminal $\alpha$-galactosylmucins, which are also targeted by lytic antibodies. Nevertheless, the T. cruzi parasites can avoid the killing induced by human anti- $\alpha$-galactosyl antibodies by the highly sialylated negatively charged surface (Chioccola et al., 2000; Buscaglia et al., 2006).

Interestingly, recent data demonstrate that during T. cruzi infection, $\mathrm{B} 220^{+} \mathrm{CD} 19^{+} \mathrm{B}$ cells can produce IL-17, a cytokine 
involved in the protective response against the parasite (ToselloBoari et al., 2012; Bermejo et al., 2013; Erdmann et al., 2013) (Figure 2C). Increased levels of IL-17 in the infection seems to be driven by active-TS acting on CD45 mucins located on $\mathrm{B} 220^{+} \mathrm{CD} 19^{+} \mathrm{B}$ cell surface, in a ROR- $\gamma \mathrm{t} / \mathrm{AhR}$-independent manner (Bermejo et al., 2013). Despite that this type of B cells could be considered as innate cells, such results point out that $\mathrm{B}$ cells and different CD45 isoforms are also targets of T. cruzi-TS activity (Freire-de-Lima et al., 2010; Muia et al., 2010).

Differentiation, homeostasis and activation processes of $\mathrm{T}$ cells greatly depend on the sialylation process. Thus, T. cruziTS-mediated modifications of the T cell sialophenotype indeed influence the host immune response.

During acute phase of T. cruzi infection, T cells become anergic and undergo clonal deletion. Moreover, $\mathrm{T}$ cells exhibit low IL-2 expression and are more prone to suffer apoptosis after activation (Nunes et al., 1998; Alcaide and Fresno, 2004). Interestingly, the induction of $\mathrm{CD}^{+} \mathrm{Th} 1$ and $\mathrm{CD}^{+}$cytotoxic T-cell protective responses is partly elicited by TS (Rodrigues et al., 1999). Both active- and inactive-TS forms engage the CD43 sialomucin in $\mathrm{CD} 4{ }^{+} \mathrm{T}$ cells, favoring their activation (Figure 2D). Such mechanism is shown to be able to rescue $\mathrm{T}$ cells from activation-induced cell death, intensifying the mitogenic capacity of these lymphocytes (Todeschini et al., 2002). Furthermore, the antigen-specific $\mathrm{CD} 8^{+} \mathrm{T}$ cell responses are regulated by a distinct sialylation process (Moody et al., 2001; Pappu and Shrikant, 2004). During $\mathrm{T}$ cell activation, the expression of SAcs on lymphocyte surface is downregulated, leading to the exposure of desialylated glycans (Priatel et al., 2000). Such decreased sialylation process is important to augment the reactivity of $\mathrm{T}$ cells for their cognate peptide in the context of MHC class
I molecules (Kao et al., 2005). In this context, recent studies showed that TS is able to re-sialylate the surface of $\mathrm{CD}^{+} \mathrm{T}$ lymphocytes, limiting the acquisition of antigen-specific $\mathrm{CD}^{+} \mathrm{T}$ cell responses (Figure 2D). These findings suggest that the resialylation ability of TS over activated T cells is an important parasite evasion strategy that directly influences the T. cruzi half-life time inside the host by preventing the immune control elicited by $\mathrm{CD}^{+} \mathrm{T}$ cells (Freire-de-Lima et al., 2010). In fact, a large number of epitopes recognized by $\mathrm{CD} 8^{+} \mathrm{T}$ cells in both experimental T. cruzi models and human disease is encoded by the TS family of genes, although the studies reveal that the epitope immunodominance of TS members varies according to the parasite strain (Martin et al., 2006).

\section{ROLE OF Trypanosoma cruzi TRANS-SIALIDASE IN THE T. cruzi-DRIVEN THYMIC ATROPHY AND DEVELOPMENT OF UNCONVENTIONAL EXTRATHYMIC T CELL SUBSETS IN CHAGAS DISEASE}

The thymus is the primary lymphoid organ where bone marrow-derived $\mathrm{T}$ cell precursors undergo differentiation. As a result of this process, positively $\mathrm{CD} 4^{+}$and $\mathrm{CD}^{+}$selected thymocytes migrate as mature $\mathrm{T}$ cells to $\mathrm{T}$-cell areas of peripheral lymphoid organs (Savino and Dardenne, 2000). Several infectious pathologies, including Chagas' disease, promote disturbances of the intrathymic compartment (Savino, 2006). During the acute phase of murine T. cruzi infection is commonly observed

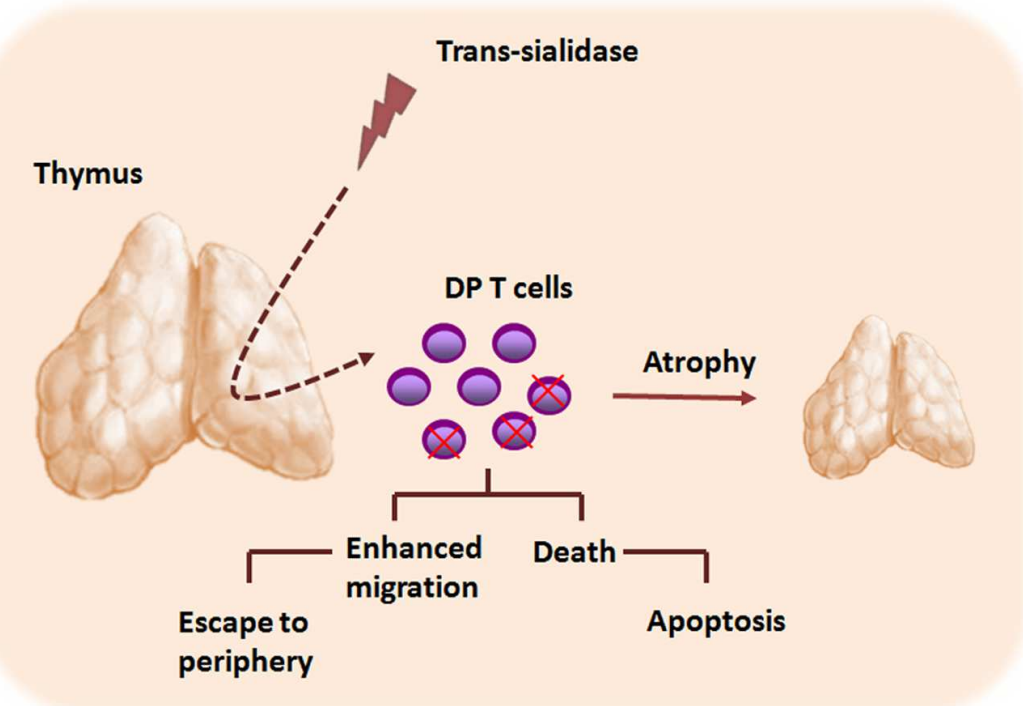

FIGURE 3 | Trypanosoma cruzi TS contributes to the thymic atrophy seen during acute phase of Chagas disease. The thymic atrophy caused by $T$. cruzi parasite is a complex phenomenon and involves several host-parasite molecule interactions, including those elicited by TS. TS promotes CD4 ${ }^{+}$CD ${ }^{+}$double positive (DP) cells apoptosis within the thymic nurse cell complex, contributing to the thymic atrophy process. Moreover, TS also modulates the migratory properties of thymocytes, and may contribute to the abnormal release of DP thymocytes to the periphery. 
an intense thymic atrophy, mainly caused by the depletion of immature $\mathrm{CD}^{+}{ }^{+} \mathrm{CD} 8^{+}$double-positive (DP) thymocytes. Such phenomenon involves not only thymocyte death but also their abnormal proliferation and migration responses (Leite de Moraes et al., 1991; Roggero et al., 2002; Henriques-Pons et al., 2004).

Interestingly, changes in the cell surface sialylation caused by TS seem also to play an important role in T. cruzi-induced morphological and phenotypic thymic alterations (Figure 3). When TS is artificially shedding to circulation, the parasite enzyme is able to induce apoptosis of thymocytes. In addition, even when TS doses became undetectable, thymic apoptosis could also be observed (Leguizamón et al., 1999). Moreover, TS-treated animals displayed enhanced thymocyte apoptosis within the thymic nurse cell complexes, findings resembling thymic alterations in infected animals. Additionally, the TS treatment was able to promote a decrease of thymocyte proliferative ratios after Concanavalin A stimulation, in a similar manner to those observed in the experimental models of T. cruzi infection. The use of TS-neutralizing antibodies apparently rescued the normal thymocyte proliferation indexes (Mucci et al., 2002). Importantly, the thymocyte apoptosis induced by TS depends on androgens, since TS administration in both female and androgen-depleted mice did not result in the increase of thymocyte death. Furthermore, lactitol, a competitive inhibitor of TS that blocks the transference of sialyl residues by TS, was able to prevent the thymic cell depletion induced by T. cruzi (Mucci et al., 2005, 2006). Further studies showed that a rise in the glucocorticoid levels, as consequence of infective stress, is also involved in the T. cruzi-driven thymic atrophy (Roggero et al., 2006; Pérez et al., 2007; Lepletier et al., 2013). Interestingly, it has been reported that glucocorticoids can change the expression of sialylated and nonsialylated Lewis (a) epitopes of adhesion molecules involved in leukocyte migration processes (Delbrouck et al., 2002). Whether similar results occur during $T$. cruzi-driven thymic atrophy it remains to be determined.

Finally, recently studies from our group revealed that TS influences the thymocyte differentiation process via activation of MAPK signaling pathways, increasing thymocyte migratory activity by inducing actin filament mobilization. Such effects were also related to the ability of TS to modulate the adhesive properties of thymocytes to thymic epithelial cells. Moreover, we found increased frequencies of activated DPT cells in the blood of chronic chagasic patients with heart disease, in association to elevated titters of anti-TS antibodies as compared to healthy individuals (Nardy et al., 2013). These findings suggest a probably role for TS in the intrathymic maturation disturbances and subsequent abnormal thymic exit of immature thymocytes seen in T. cruzi infection.

\section{REFERENCES}

Albertti, L. A., Macedo, A. M., Chiari, E., Andrews, N. W., and Andrade, L. O. (2010). Role of host lysosomal associated membrane protein (LAMP) in Trypanosoma cruzi invasion and intracellular

\section{CONCLUDING REMARKS}

A successful establishment of an infection relies on efficient strategies adopted by the infectious agents to evade early their detection by the host immune system. Considering that protozoans are the most ancient members of the animal kingdom, it is conceivable to think that they evolved sophisticated mechanisms to ensure their survival as intracellular parasites. T. cruzi is part a diverse group of unicellular organisms that can modify host cells to their own benefits (Jackson, 2015). In this review, we highlighted important aspects of $T$. cruzi immune evasion involving TS, a major parasite virulence factor. The diverse functions displayed by this molecule enable the parasite to interfere in many crucial host biological processes, including those responsible for protective immune responses. Despite several years of research directed toward understanding the role of T. cruzi-derived TS on the host-parasite interplay, there are still some points to be uncovered, especially those involving the distribution of genes encoding TS in different parasite strains. This question becomes even more important if we consider the coexistence of different T. cruzi strains in their natural reservoirs (Noireau et al., 2009). The existence of antigen variation within the parasite population, may lead the expression of competing $\mathrm{T}$ cell epitopes with different affinities to MHC molecules that could influence the acquisition of protective adaptive immune responses. Given the importance of TS for the establishment of an efficient infection, this molecule has gained potential attention as a drug target for disease therapies. Thus, efforts to understand the biology of TS would strengthen the use of TS inhibitors in therapeutic approaches for treatment of Chagas disease.

\section{AUTHOR CONTRIBUTIONS}

$\mathrm{AN}, \mathrm{CF}$, and AP wrote the paper. AM made substantial contributions to the conception of the work. All authors read and approved the final version of the manuscript.

\section{FUNDING}

This work was supported by grants from Conselho Nacional de Desenvolvimento Científico e Tecnológico do Brasil (CNPq) and Fundação de Amparo à Pesquisa do Estado do Rio de Janeiro (FAPERJ).

\section{ACKNOWLEDGMENTS}

We thank Florencia González for his technical assistance. Dr. AM and Dr. CF are recipients of fellowships from CNPq.

development. Microbes Infect. 12, 784-789. doi: 10.1016/j.micinf.2010. 05.015

Alcaide, P., and Fresno, M. (2004). The Trypanosoma cruzi membrane mucin AgC10 inhibits T cell activation and IL-2 transcription through L-selectin. Int. Immunol. 16, 1365-1375. doi: 10.1093/intimm/dxh138 
Alvarez, M. N., Peluffo, G., Piacenza, L., and Radi, R. (2011). Intraphagosomal peroxynitrite as a macrophage derived cytotoxin against internalized Trypanosoma cruzi: consequences for oxidative killing and role of microbial peroxiredoxins in infectivity. J. Biol. Chem. 286, 6627-6640. doi: 10.1074/jbc.M110.167247

Alvarez, P., Leguizamon, M. S., Buscaglia, C. A., Pitcovsky, T. A., and Campetella, O. (2001). Multiple overlapping epitopes in the repetitive unit of the shed acute-phase antigen from Trypanosoma cruzi enhance its immunogenic properties. Infect. Immun. 69, 7946-7949. doi: 10.1128/IAI.69.12.7946-7949.2001

Amon, R., Reuven, E. M., Ben-Arye, S. L., and Padler-Karavani, V. (2014). Glycans in immune recognition and response. Carbohydr. Res. 389, 115-122. doi: 10.1016/j.carres.2014.02.004

Andrews, N. W., and Whitlow, M. B. (1989). Secretion of Trypanosoma cruzi of a hemolysin active at low pH. Mol. Biochem. Parasitol. 33, 249-256. doi: 10.1016/0166-6851(89)90086-8

Atwood, J. A., Weatherly, D. B., Minning, T. A., Bundy, B., Cavola, C., Opperdoes, F. R., et al. (2005). The Trypanosoma cruzi proteome. Science 309, 473-476. doi: 10.1126/science.1110289

Barrias, E. S., de Carvalho, T. M., and De Souza, W. (2013). Trypanosoma cruzi: entry into mammalian host cells and parasitophorous vacuole formation. Front. Immunol. 4:186. doi: 10.3389/fimmu.2013.00186

Bermejo, D. A., Jackson, S. W., Gorosito-Serran, M., Acosta-Rodriguez, E. V., Amezcua-Vesely, M. C., Sather, B. D., et al. (2013). Trypanosoma cruzi transsialidase initiates a program independent of the transcription factors ROR $\gamma \mathrm{t}$ and Ahr that leads to IL-17 production by activated B cells. Nat. Immunol. 14, 514-522. doi: 10.1038/ni.2569

Burleigh, B. A., and Andrews, N. W. (1995). The mechanisms of Trypanosoma cruzi invasion of mammalian cells. Ann. Rev. Microbiol. 49, 175-200. doi: 10.1146/annurev.mi.49.100195.001135

Buscaglia, C. A., Alfonso, J., Campetella, O., and Frasch, A. C. (1999). Tandem amino acid repeats from Trypanosoma cruzi shed antigens increase the half-life of proteins in blood. Blood 93, 2025-2032.

Buscaglia, C. A., Campo, V. A., Frasch, A. C., and Di Noia, J. M. (2006). Trypanosoma cruzi surface mucins: host-dependent coat diversity. Nat. Rev. Microbiol. 4, 229-236. doi: 10.1038/nrmicro1351

Buschiazzo, A., Amaya, M. F., Cremona, M. L., Frasch, A. C., and Alzari, P. M. (2002). The crystal structure and mode of action of trans-sialidase, a key enzyme in Trypanosoma cruzi pathogenesis. Mol. Cell 10, 757-768. doi: 10.1016/S10972765(02)00680-9

Chioccola, V. L. P., Acosta-Serrano, A., Almeida, I. C., Ferguson, M. A. J., SoutoPadron, T., Rodrigues, M. M., et al. (2000). Mucin-like molecules form a negatively charged coat that protects Trypanosoma cruzi trypomastigotes from killing by human anti-alpha-galactosyl antibodies. J. Cell Sci. 113, 1299-1307.

Coura, J. R., and Borges-Pereira, J. (2010). Chagas disease: 100 years after its discovery. A systemic review. Acta Trop. 115, 5-13. doi: 10.1016/j.actatropica.2010.03.008

Cremona, M. L., Campetell, A. O., Sánchez, D. O., and Frasch, A. C. (1999). Enzymically inactive members of the trans-sialidase family from Trypanosoma cruzi display beta-galactose binding activity. Glycobiology 9, 581-587. doi: 10.1093/glycob/9.6.581

Cremona, M. L., Sánchez, D. O., Frasch, A. C., and Campetella, O. (1995). A single tyrosine differentiates active and inactive Trypanosoma cruzi trans-sialidases. Gene 160, 123-128. doi: 10.1016/0378-1119(95)00175-6

de Souza, W., de Carvalho, T. M., and Barrias, E. S. (2010). Review on Trypanosoma cruzi: host cell interaction. Int. J. Cell Biol. 2010, 295394. doi: $10.1155 / 2010 / 295394$

Delbrouck, C., Kaltner, H., Danguy, A., Nifant'ev, N. E., Bovin, N. V., and Vandenhoven, G. (2002). Glucocorticoid-induced differential expression of the sialylated and nonsialylated Lewis(a) epitopes and respective binding sites in human nasal polyps maintained under ex vivo tissue culture conditions. Ann. Otol. Rhinol. Laryngol. 111, 1097-1107. doi: 10.1177/000348940211101207

Devera, R., Fernandes, O., and Coura, J. R. (2003). Should Trypanosoma cruzi be called "cruzi" complex? A review of the parasite diversity and the potential of selecting population after in vitro culturing and mice infection. Mem. Inst. Oswaldo Cruz 98, 1-12. doi: 10.1590/S0074-02762003000100001

El-Sayed, N. M., Myler, P. J., Bartholomeu, D. C., Nilsson, D., Aggarwal, G., Tran, A. N., et al. (2005). The genome sequence of Trypanosoma cruzi, etiologic agent of Chagas disease. Science 309, 409-415. doi: 10.1126/science. 1112631

Erdmann, H., Roßnagel, C., Böhme, J., Iwakura, Y., Jacobs, T., Schaible, U. E., et al. (2013). IL-17A promotes macrophage effector mechanisms against Trypanosoma cruzi by trapping parasites in the endolysosomal compartment. Immunobiology 218, 910-923. doi: 10.1016/j.imbio.2012.10.005

Erdmann, H., Steeg, C., Koch-Nolte, F., Fleischer, B., and Jacobs, T. (2009). Sialylated ligands on pathogenic Trypanosoma cruzi interact with SiglecE (sialic acid binding Ig-like lectin-E). Cell. Microbiol. 11, 1600-1611. doi: $10.1111 / \mathrm{j} .1462-5822.2009 .01350 . \mathrm{x}$

Esko, J., and Sharon, N. (2009). "Microbial lectins: hemagglutinins, adhesins, and toxins," in Essentials of Glycobiology, 2nd Edn, eds A. Varki, R. D. Cummings, J. D. Esko, H. H. Freeze, P. Stanley, C. R. Bertozzi, et al. (Cold Spring Harbor, NY: Cold Spring Harbor Laboratory Press).

Frasch, A. C. (2000). Functional diversity in the trans-sialidase and mucin families in Trypanosoma cruzi. Parasitol. Today 16, 282-286. doi: 10.1016/S01694758(00)01698-7

Freire-de-Lima, L., Alisson-Silva, F., Carvalho, S. T., Takiya, C. M., Rodrigues, M. M., DosReis, G. A., et al. (2010). Trypanosoma cruzi subverts host cell sialylation and may compromise antigen-specific CD8 $+\mathrm{T}$ cell responses. J. Biol. Chem. 285, 13388-13396. doi: 10.1074/jbc.M109.096305

Freire-de-Lima, L., Fonseca, L. M., Oeltmann, T., Mendonça-Previato, L., and Previato, J. O. (2015). The trans-sialidase, the major Trypanosoma cruzi virulence factor: three decades of studies. Glycobiology 25, 1142-1149. doi: 10.1093/glycob/cwv057

Freitas, A. A., and Rocha, B. (2000). Population biology of lymphocytes: the fight for survival. Annu. Rev. Immunol. 18, 83-111. doi: 10.1146/annurev.immunol.18.1.83

Freitas, L. M., dos Santos, S. L., Rodrigues-Luiz, G. F., Mendes, T. A. O., Rodrigues, T. S., Gazzinelli, R. T., et al. (2011). Genomic analyses, gene expression and antigenic profile of the trans-sialidase superfamily of Trypanosoma cruzi reveal an undetected level of complexity. PLOS ONE 6:e25914. doi: 10.1371/journal.pone.0025914

Gao, W., and Pereira, M. A. (2001). Trypanosoma cruzi trans-sialidase potentiates $\mathrm{T}$ cell activation through antigen presenting cells: role of IL-6 and Bruton's tyrosine kinase. Eur. J. Immunol. 31, 1503-1512. doi: 10.1002/15214141(200105)31:5<1503::AID-IMMU1503>3.0.CO;2-W

Gao, W., Wortis, H. H., and Pereira, M. A. (2002). The Trypanosoma cruzi transsialidase is a T cell-independent B cell mitogen and an inducer of non-specific Ig secretion. Int. Immunol. 14, 299-308. doi: 10.1093/intimm/14.3.299

Hall, B. F., Webster, P., Ma, A. K., Joiner, K. A., and Andrews, N. W. (1992). Desialylation of lysosomal membrane glycoproteins by Trypanosoma cruzi: a role for the surface neuraminidase in facilitating parasite entry into the host cell cytoplasm. J. Exp. Med. 176, 313-325. doi: 10.1084/jem.176.2.313

Henriques-Pons, A., De Meis, J., Cotta-De-Almeida, V., Savino, W., and AraujoJorge, T. C. (2004). Fas and perforin are not required for thymus atrophy induced by Trypanosoma cruzi infection. Exp. Parasitol. 107, 1-4. doi: 10.1016/j.exppara.2004.04.010

Jackson, A. P. (2015). The evolution of parasite genomes and the origins of parasitism. Parasitology 142(Suppl. 1), S1-S5. doi: 10.1017/S003118201 4001516

Kao, C., Daniels, M. A., and Jameson, S. C. (2005). Loss of CD8 and TCR binding to Class I MHC ligands following T cell activation. Int. Immunol. 17, 1607-1617. doi: 10.1093/intimm/dxh340

Kipnis, T. L., David, J. R., Alper, C. A., Sher, A., and da Silva, W. D. (1981). Enzymatic treatment transforms trypomastigotes of Trypanosoma cruzi into activators of alternative complement pathway and potentiates their uptake by macrophages. Proc. Natl. Acad. Sci. U.S.A. 78, 602-605. doi: 10.1073/pnas.78.1.602

Leguizamón, M. S., Mocetti, E., GarcíaRivello, H., Argibay, P., and Campetella, O. (1999). Trans-sialidase from Trypanosoma cruzi induces apoptosis in cells from the immune system in vivo. J. Infect. Dis. 180, 1398-1402. doi: 10.1086/3 15001

Leite de Moraes, M. C., Hontebeyrie-Joskowicz, M., Leboulenger, F., Savino, W., Dardenne, M., and Lepault, F. (1991). Studies on the thymus in Chagas' disease. II. Thymocyte subset fluctuations in Trypanosoma cruzi-infected mice: relationship to stress. Scand. J. Immunol. 33, 267-275. doi: 10.1111/j.13653083.1991.tb01772.x 
Lepletier, A., de Carvalho, V. F., Rodrigues e Silva, P. M., Villar, S., Pérez, A. R., Savino, W., et al. (2013). Trypanosoma cruzi disrupts thymic homeostasis by altering intrathymic and systemic stress-related endocrine circuitries. PLoS Negl. Trop. Dis. 7:e2470. doi: 10.1371/journal.pntd.000 2470

Maleckar, J. R., and Kierszenbaum, F. (1983). Inhibition of mitogen-induced proliferation of mouse $\mathrm{T}$ and $\mathrm{B}$ lymphocytes by bloodstream forms of Trypanosoma cruzi. J. Immunol. 130, 908-911.

Martin, D. L., Weatherly, D. B., Laucella, S. A., Cabinian, M. A., Crim, M. T., Sullivan, S., et al. (2006). CD8+ T-Cell responses to Trypanosoma cruzi are highly focused on strain-variant trans-sialidase epitopes. PLoS Pathog. 2:e77. doi: 10.1371/journal.ppat.0020077

Ming, M., Chuenkova, M., Ortega-Barria, E., and Pereira, M. E. (1993). Mediation of Trypanosoma cruzi invasion by sialic acid on the host cell and trans-sialidase on the trypanosome. Mol. Biochem. Parasitol. 59, 243-252.

Montaudouin, C., Anson, M., and Hao, Y. (2013). Quorum sensing contributes to activated IgM-secreting B cell homeostasis. J. Immunol. 190, 106-114. doi: 10.4049/jimmunol.1200907

Moody, A. M., Chui, D., Reche, P. A., Priatel, J. J., Marth, J. D., and Reinherz, E. L. (2001). Developmentally regulated glycosylation of the CD8 $\alpha \beta$ coreceptor stalk modulates ligand binding. Cell 107, 501-512. doi: 10.1016/S00928674(01)00577-3

Mucci, J., Hidalgo, A., Mocetti, E., Argibay, P. F., Leguizamon, M. S., and Campetella, O. (2002). Thymocyte depletion in Trypanosoma cruzi infection is mediated by trans sialidase-induced apoptosis onnurse cells complex. Proc. Natl. Acad. Sci. U.S.A. 99, 3896-3901. doi: 10.1073/pnas.052496399

Mucci, J., Mocetti, E., Leguizamón, M. S., and Campetella, O. (2005). A sexual dimorphism in intrathymic sialylation survey is revealed by the trans-sialidase from Trypanosoma cruzi. J. Immunol. 174, 4545-4550. doi: 10.4049/jimmunol.174.8.4545

Mucci, J., Risso, M. G., Leguizamón, M. S., Frasch, A. C., and Campetella, O. (2006). The trans-sialidase from T. cruzi triggers apoptosis by target cell sialylation. Cell. Microbiol. 8, 1086-1095. doi: 10.1111/j.1462-5822.2006.00689.x

Muia, R. P., Yu, H., Prescher, J. A., Hellman, U., Chen, X., Bertozzi, C. R., et al. (2010). Identification of glycoproteins targeted by Trypanosoma cruzi transsialidase, a virulence factor that disturbs lymphocyte glycosylation. Glycobiology 20, 833-842. doi: 10.1093/glycob/cwq037

Nagajyothi, F., Machado, F. S., Burleigh, B. A., Jelicks, L. A., Scherer, P. E., Mukherjee, S., et al. (2012). Mechanisms of Trypanosoma cruzi persistence in Chagas disease. Cell. Microbiol. 14, 634-643. doi: 10.1111/j.14625822.2012.01764.x

Nardy, A. F. F., da Silva Filho, J. L., Pérez, A. R., de Meis, J., Farias-deOliveira, D. A., Penha, L., et al. (2013). Trans-sialidase from Trypanosoma cruzi enhances the adhesion properties and fibronectin-driven migration of thymocytes. Microbes Infect. 15, 365-374. doi: 10.1016/j.micinf.2013. 02.003

Noireau, F., Diosque, P., and Jansen, A. M. (2009). Trypanosoma cruzi: adaptation to its vectors and its hosts. Vet. Res. 40, 26. doi: 10.1051/vetres/2009009

Norris, K. A. (1998). Stable transfection of Trypanosoma cruzi epimastigotes with the trypomastigote-specific complement regulatory protein cDNA confers complement resistance. Infect. Immun. 66, 2460-2465.

Nunes, M. P., Andrade, R. M., Lopes, M. F., and DosReis, G. A. (1998). Activationinduced T cell death exacerbates Trypanosoma cruzi replication in macrophages cocultured with CD4+ T lymphocytes from infected hosts. J. Immunol. 160, 1313-1319.

Oladiran, A., and Belosevic, M. (2012). Immune evasion strategies of trypanosomes: a review. J. Parasitol. 98, 284-292. doi: 10.1645/GE-2925.1

Oppezzo, P., Obal, G., Baraibar, M. A., Pritsch, O., Alzari, P. M., and Buschiazzo, A. (2011). Crystal structure of an enzymatically inactive trans-sialidase-like lectin from Trypanosoma cruzi: the carbohydrate binding mechanism involves residual sialidase activity. Biochim. Biophys. Acta 1814, 1154-1161. doi: 10.1016/j.bbapap.2011.04.012

Ortiz-Ortiz, L., Parks, D. E., Rodriguez, M., and Weigle, W. O. (1980). Polyclonal B lymphocyte activation during Trypanosoma cruzi infection. J. Immunol. 124, 121-126.

Pappu, B. P., and Shrikant, P. A. (2004). Alteration of cell surface sialylation regulates antigen-induced naive $\mathrm{CD} 8+\mathrm{T}$ cell responses. J. Immunol. 173, 275-284. doi: 10.4049/jimmunol.173.1.275
Parodi, A. J., Pollevick, G. D., Mautner, M., Buschiazzo, A., Sanchez, D. O., and Frasch, A. C. (1992). Identification of the gene(s) coding for the trans-sialidase of Trypanosoma cruzi. EMBO J. 11, 1705-1710.

Pereira, M. E. (1983). A developmentally regulated neuraminidase activity in Trypanosoma cruzi. Science 219, 1444-1446. doi: 10.1126/science.6338592

Pereira, M. E., Loures, M. A., Villalta, F., and Andrade, A. F. (1980). Lectin receptors as markers for Trypanosoma cruzi. Developmental stages and a study of the interaction of wheat germ agglutinin with sialic acid residues on epimastigote cells. J. Exp. Med. 152, 1375-1392. doi: 10.1084/jem.152. 5.1375

Pereira, M. E., Mejia, J. S., Ortega-Barria, E., Matzilevich, D., and Prioli, R. P. (1991). The Trypanosoma cruzi neuraminidase contains sequences similar to bacterial neuraminidases, YWTD repeats of the low density lipoprotein receptor, and type III modules offibronectin. J. Exp. Med. 174, 179-191. doi: 10.1084/jem.174.1.179

Pereira-Chioccola, V. L., Schenkman, S., and Kloetzel, J. (1994). Sera from chronic Chagasic patients and animals infected with Trypanosoma cruzi inhibit trans-sialidase by recognizing its catalyticdomain. Infect. Immun. 62, 29 73-2978.

Pérez, A. R., Roggero, E., Nicora, A., Palazzi, J., Besedovsky, H. O., del Rey, A., et al. (2007). Thymus atrophy during Trypanosoma cruzi infection is caused by an immuno-endocrine imbalance. Brain Behav. Immun. 21, 890-900. doi: 10.1016/j.bbi.2007.02.004

Piacenza, L., Zago, M. P., Peluffo, G., Alvarez, M. N., Basombrio, M. A., and Radi, R. (2009). Enzymes of the antioxidant network as novel determiners of Trypanosoma cruzi virulence. Int. J. Parasitol. 39, 1455-1464. doi: 10.1016/j.ijpara.2009.05.010

Pollevick, G. D., Affranchino, J. L., Frasch, A. C. C., and Sanchez, D. O. (1991). The complete sequence of a shed acute-phase antigen of Trypanosoma cruzi. Mol. Biochem. Parasitol. 47, 247-250. doi: 10.1016/0166-6851(91)90185-9

Previato, J. O., Andrade, A. F., Pessolani, M. C., and Mendonça-Previato, L. (1985). Incorporation of sialic acid into Trypanosoma cruzi macromolecules. A proposal for a new metabolic route. Mol. Biochem. Parasitol. 16, 85-96. doi: 10.1016/0166-6851(85)90051-9

Priatel, J. J., Chui, D., Hiraoka, N., Simmons, C. J., Richardson, K. B., Page, D. M., et al. (2000). The ST3Gal-I sialyltransferase controls CD8+ T lymphocyte homeostasis by modulating O-glycan biosynthesis. Immunity 12, 273-283. doi: 10.1016/S1074-7613(00)80180-6

Ribeirão, M., Pereira-Chioccola, V. L., Eichinger, D., Rodrigues, M. M., and Schenkman, S. (1997). Temperature differences for trans-glycosylation and hydrolysis reaction reveal an acceptor binding site in the catalytic mechanism of Trypanosoma cruzi trans-sialidase. Glycobiology 7, 1237-1246. doi: 10.1093/glycob/7.8.1237

Ribeirão, M., Pereira-Chioccola, V. L., Renia, L., Augusto Fragata Filho, A., Schenkman, S., and Rodrigues, M. M. (2000). Chagasic patients develop a type 1 immune response to Trypanosoma cruzi trans-sialidase. Parasite Immunol. 22, 49-53. doi: 10.1046/j.1365-3024.2000.00260.x

Ribeiro, A. L., Nunes, M. P., Teixeira, M. M., and Rocha, M. O. (2012). Diagnosis and management of Chagas disease and cardiomyopathy. Nat. Rev. Cardiol. 9, 576-589. doi: 10.1038/nrcardio.2012.109

Risso, M. G., Pitcovsky, T. A., Caccuri, R. L., Campetella, O., and Leguizamon, M. S. (2007). Immune system pathogenesis is prevented by the neutralization of the systemic trans-sialidase from Trypanosoma cruzi during severe infections. Parasitology 134, 503-510. doi: 10.1017/S0031182006001752

Roggero, E., Pérez, A. R., Tamae-Kakazu, M., Piazzon, I., Nepomnaschy, I., Besedovsky, H. O., et al. (2006). Endogenous glucocorticoids cause thymus atrophy but are protective during acute Trypanosoma cruzi infection. J. Endocrinol. 190, 495-503. doi: 10.1677/joe.1.06642

Rodrigues, M. M., Ribeirão, M., Pereira-Chioccola, V. L., Renia, L., and Costa, F. (1999). Predominance of CD4 Th1 and CD8 TC1 cells revealed by characterization of the cellular immune response generated by immunization with a DNA vaccine containing a Trypanosoma cruzi gene. Infect. Immun. 67, 3855-3863.

Roggero, E., Perez, A., Tamae-Kakazu, M., Piazzon, I., Nepomnaschy, I., Wietzerbin, J., et al. (2002). Differential susceptibility to acute Trypanosoma cruzi infection in BALB/c and C57BL/6 mice is not associated with a distinct parasite load but cytokine abnormalities. Clin. Exp. Immunol. 128, 421-428. doi: 10.1046/j.1365-2249.2002.01874.x 
Rubin-de-Celis, S. S., Uemura, H., Yoshida, N., and Schenkman, S. (2006). Expression of trypomastigote trans-sialidase in metacyclic forms of Trypanosoma cruzi increases parasite escape from its parasitophorous vacuole. Cell. Microbiol. 8, 1888-1898. doi: 10.1111/j.1462-5822.2006.00755.x

Savino, W. (2006). The thymus is a common target organ in infectious diseases. PLoS Pathog. 2:e62. doi: 10.1371/journal.ppat.0020062

Savino, W., and Dardenne, M. (2000). Neuroendocrine control of thymus physiology 1. Endocr. Rev. 21, 412-443. doi: 10.1210/edrv.21.4.0402

Schauer, R., Reuter, G., Muhlpfordt, H., Andrade, A. F., and Pereira, M. E. (1983). The occurrence of N-acetyl- and N-glycoloylneuraminic acid in Trypanosoma cruzi. Hoppe Seylers Z. Physiol. Chem. 364, 1053-1057. doi: 10.1515/bchm2.1983.364.2.1053

Schenkman, R. P., Vandekerckhove, F., and Schenkman, S. (1993). Mammalian cell sialic acid enhances invasion by Trypanosoma cruzi. Infect. Immun. 61, 898-902.

Schenkman, S., Jiang, M. S., Hart, G. W., and Nussenzweig, V. (1991). A novel cell surface trans-sialidase of Trypanosoma cruzi generates a stage-specific epitope required for invasion of mammalian cells. Cell 65, 1117-1125. doi: 10.1016/0092-8674(91)90008-M

Schenkman, S., Pontes de Carvalho, L., and Nussenzweig, V. (1992). Trypanosoma cruzi trans-sialidase and neuraminidase activities can be mediated by the same enzymes. J. Exp. Med. 175, 567-575. doi: 10.1084/jem.175.2.567

Tardieux, I., Webster, P., Ravesloot, J., Boron, W., Lunn, J. A., Heuser, J. E., et al. (1992). Lysosome recruitment and fusion are early events required for trypanosome invasion of mammalian cells. Cell 71, 1117-1130. doi: 10.1016/S0092-8674(05)80061-3

Tarleton, R. L., Reithinger, R., Urbina, J. A., Kitron, U., and Gurtler, R. E. (2007). The challenges of Chagas disease: grim outlook or glimmer of hope? PLoS Med. 4:e332. doi: 10.1371/journal.pmed.0040332

Todeschini, A. R., Nunes, M. P., Pires, R. S., Lopes, M. F., Previato, J. O., Mendonça-Previato, L., et al. (2002). Costimulation of host T lymphocytes by a trypanosomal trans-sialidase: involvement of CD43 signaling. J. Immunol. 168, 5192-5198. doi: 10.4049/jimmunol.168.10.5192
Tomlinson, S., Pontes de Carvalho, L. C., Vandekerckhove, F., and Nussenzweig, V. (1994). Role of sialic acid in the resistance of Trypanosoma cruzi trypomastigotes to complement. J. Immunol. 153, 3141-3147.

ToselloBoari, J., AmezcuaVesely, M. C., Bermejo, D. A., Ramello, M. C., Montes, C. L., Cejas, H., et al. (2012). IL-17RA signaling reduces inflammation and mortality during Trypanosoma cruzi infection by recruiting suppressive IL-10-producing neutrophils. PLoS Pathog. 8:e1002658. doi: 10.1371/journal.ppat.1002658

Tribulatti, M. V., Mucci, J., Van Rooijen, N., Leguizamon, M. S., and Campetella, O. (2005). The trans-sialidase from Trypanosoma cruzi induces thrombocytopenia during acute Chagas' disease by reducing the platelet sialic acid contents. Infect. Immun. 73, 201-207. doi: 10.1128/IAI.73.1.201-207. 2005

Tyler, K. M., and Engman, D. M. (2001). The life cycle of Trypanosoma cruzi revisited. Int. J. Parasitol. 31, 472-481. doi: 10.1016/S0020-7519(01)00153-9

Uemura, H., Schenkman, S., Nussenzweig, V., and Eichinger, D. (1992). Only some members of a gene family in Trypanosoma cruzi encode proteins that express both trans-sialidase and neuraminidase activities. EMBO J. 11, 3837-3844.

Varki, A. (1997). Sialic acids as ligands in recognition phenomena. FASEB J. 11, 248-255.

Vimr, E., and Lichtensteiger, C. (2002). To sialylate, or not to sialylate: that is the question. Trends Microbiol. 10, 254-257. doi: 10.1016/S0966-842X(02)02361-2

Conflict of Interest Statement: The authors declare that the research was conducted in the absence of any commercial or financial relationships that could be construed as a potential conflict of interest.

Copyright (c) 2016 Nardy, Freire-de-Lima, Pérez and Morrot. This is an open-access article distributed under the terms of the Creative Commons Attribution License (CC BY). The use, distribution or reproduction in other forums is permitted, provided the original author(s) or licensor are credited and that the original publication in this journal is cited, in accordance with accepted academic practice. No use, distribution or reproduction is permitted which does not comply with these terms. 